\title{
Pulmonary function and exercise capacity in survivors of congenital diaphragmatic hernia
}

\author{
M.G. Peetsold*, H.A. Heij ${ }^{\#}$, A.F. Nagelkerke*, H. IJsselstijn ${ }^{\star}$, D. Tibboel", \\ P.H. Quanjer ${ }^{+}$and R.J.B.J. Gemke*
}

ABSTRACT: Congenital diaphragmatic hernia $(\mathrm{CDH})$ is associated with pulmonary hypoplasia and pulmonary hypertension. The objective of this study was to assess pulmonary function and exercise capacity and its early determinants in children and adolescents born with high-risk $\mathrm{CDH}$ ( $\mathrm{CDH}$-associated respiratory distress within the first $24 \mathrm{~h}$ ) and to explore the relationship of these findings with CDH severity.

Of 159 patients born with high-risk $\mathrm{CDH}, 84$ survived. Of the 69 eligible patients, 53 children (mean \pm SD age $11.9 \pm 3.5$ yrs) underwent spirometry, lung volume measurements and maximal cardiopulmonary exercise testing (CPET). Results of the pulmonary function tests were compared with those from a healthy control group matched for sex, age and height.

CDH survivors had a significantly lower forced expiratory volume in $1 \mathrm{~s}$ (FEV 1 ), forced vital capacity (FVC), FEV1/FVC, maximum mid-expiratory flow and peak expiratory flow when compared with healthy controls. The residual volume/total lung capacity ratio was significantly higher. Linear regression analysis showed that gastro-oesophageal reflux disease was an independent determinant of reduced FEV1 and FVC. CPET results were normal in those tested.

High-risk $\mathrm{CDH}$ survivors have mild to moderate pulmonary function abnormalities when compared with a healthy matched control group, which may be related to gastro-oesophageal reflux disease in early life. Exercise capacity and gas exchange parameters were normal in those tested, indicating that the majority of patients do not have physical impairment.

KEYWORDS: Congenital diaphragmatic hernia, exercise capacity, follow-up, pulmonary function testing

ongenital diaphragmatic hernia $(\mathrm{CDH})$ is a life-threatening anomaly with a mortality rate ranging $10-50 \%$, depending on case selection [1-3]. Pulmonary hypoplasia, pulmonary hypertension and $\mathrm{CDH}$-associated malformations are major determinants of morbidity and mortality [4]. CDH is accompanied by a variable degree of hypoplasia of the ipsilateral and contralateral lung, characterised by a reduction of the number of airways, alveoli and vascular generations [5, 6]. Respiratory failure requiring ventilatory support immediately after birth is a characteristic of high-risk CDH. Many patients require high pressures and high fractions of inspiratory oxygen to provide adequate oxygenation, which may lead to further pulmonary damage $[4,7,8]$. Since the asymmetry of the lungs, due to pulmonary hypoplasia, results in areas of different compliance and therefore potential hyperinflation and overexpansion of alveoli, risk of barotrauma in $\mathrm{CDH}$ patients may even increase further [9].

$\mathrm{CDH}$ is also associated with pulmonary hypertension, which may be the result of failure of normal structural remodelling of the pressureregulating pulmonary arteries after birth, as described in deceased CDH patients [10, 11]. Scintigraphic studies have demonstrated that in $\mathrm{CDH}$ survivors, mean perfusion of the ipsilateral lung was lower when compared with healthy children [12-15] and when compared with the contralateral lung [12, 13], suggesting residual vascular abnormalities.

To improve the understanding of the long-term consequences of pulmonary hypoplasia and pulmonary vascular abnormalities, the primary objective of this study was to assess pulmonary function and exercise capacity in a group of patients aged 6-18 yrs who had undergone

\section{AFFILIATIONS}

*Dept of Paediatrics, VU University Medical Centre, Amsterdam, \#Paediatric Surgical Centre of Amsterdam, VU University Medical Centre, Emma Children's Hospital, Academic Medical Centre,

Amsterdam,

Depts of "Paediatric Surgery, and

+Paediatrics, Erasmus Medical

Centre, Sophia Children's Hospital,

Rotterdam, The Netherlands.

CORRESPONDENCE

M.G. Peetsold

Dept of Paediatrics

VU University Medical Centre

P.0. Box 7057

1007 MB Amsterdam

The Netherlands

E-mail: m.peetsold@vumc.nl

Received:

Nov 302008

Accepted after revision:

Feb 262009

First published online:

March 122009 
surgical repair of high-risk $\mathrm{CDH}$ in the neonatal period. Results of the pulmonary function tests were compared with a matched control group. The secondary objective was to explore early (particularly CDH-related) determinants of pulmonary function and/or exercise tolerance in later life.

\section{MATERIAL AND METHODS}

\section{Patients}

All patients born with high-risk $\mathrm{CDH}$ referred to the Paediatric Surgical Centre of Amsterdam (the Netherlands) between 1987 and 1999, and to the Sophia Children's Hospital in Rotterdam (the Netherlands) between 1988 and 1994, were eligible for this study. Children who were treated at the Sophia Children's Hospital after 1994 or treated with extracorporeal membrane oxygenation (ECMO) since 1991 were included in another follow-up programme and were therefore not approached. Patients were included if they developed $\mathrm{CDH}$-associated respiratory distress within the first day of life (high-risk $\mathrm{CDH}$ ). Patients were excluded if they had other serious anomalies or were incapable of adequately performing all tests.

Permission for the study was granted by the Institutional Review Board of all three participating hospitals (VU University Medical Centre, Amsterdam; Academic Medical Centre, Emma Children's Hospital, Amsterdam; and Erasmus Medical Centre, Sophia Children's Hospital, Rotterdam). Written informed consent was obtained from all patients and their parents or guardians prior to inclusion.

Patients' charts were reviewed, focusing on relevant peri- and post-natal variables.

\section{Study design}

Patients who gave informed consent attended the outpatient clinic for a study visit. Pulmonary function testing included spirometry and lung volume measurements were followed by cardiopulmonary exercise testing (CPET).

For the pulmonary function test, patients were matched for height, age and sex with schoolchildren and adolescents that had been studied independently in the past. The studies of Dutch schoolchildren [16] and of adolescents [17] have been described in detail previously. Schoolchildren were studied, with informed consent from the parents, between 1984 and 1986, and adolescents between 1978 and 1984. All matched controls were healthy and lifelong nonsmokers.

\section{Pulmonary function tests}

Patients performed standard spirometry and underwent lung volume measurements according to the guidelines of the European Coal and Steel Community (ECSC)/European Respiratory Society (ERS) [18]. All medication was discontinued $24 \mathrm{~h}$ prior to testing. Forced expiratory volume in $1 \mathrm{~s}$ (FEV1), forced vital capacity (FVC), maximum mid-expiratory flow (MMEF) and peak expiratory flow (PEF) were determined from the largest of three reproducible manoeuvres using a mass flow sensor (Vmax 229; Sensor Medics, Yorba Linda, CA, USA) [18]. Spirometry was repeated after inhalation of $4 \times 100 \mu \mathrm{g}$ salbutamol aerosol, in order to evaluate the reversibility of potential bronchial obstruction and prevent exercise-induced bronchoconstriction. A change in FEV1 $\geqslant 12 \%$, expressed as percentage of the predicted value, was considered a significant response [18].

Lung volume measurements were carried out after bronchodilation. Vital capacity (VC), total lung capacity (TLC) and residual volume (RV) were determined by the multibreath nitrogen washout method [19]. The mean of three reproducible manoeuvres was used for analysis.

Results were expressed as z-scores calculated as the difference between observed and predicted value divided by the residual standard deviation from the reference values [20]. Since STANOJEVIC et al. [20] did not provide reference values for the $\mathrm{PEF}$, these results were expressed as $\mathrm{L} \cdot \mathrm{s}^{-1}$. The $\mathrm{RV} / \mathrm{TLC}$ ratio was expressed as a percentage. Z-scores $<-1.64$ (fifth percentile of the reference population) were considered abnormally low.

In the matched controls all measurements were obtained without bronchodilation. Flow-volume curves were obtained via a dry rolling-seal spirometer in children and with a Fleisch III pneumotachometer in adolescents (both Vica Test 5, Mijnhardt, the Netherlands). In adolescents, but not in schoolchildren, RV was obtained by the forced nitrogen rebreathing technique described and validated by STERK et al. [21]. The longitudinal data of growing children [16] were used to construct a cross-section by selecting at random one record from a person's available measurements so that the new data set had an age distribution that was as uniform as possible, each person being represented only once. Thus, data were available on 123 females and 361 males. Regression equations were derived that gave the best fit to the data (table 1).

\section{Cardiopulmonary exercise testing}

Maximal exercise capacity was assessed using the Bruce treadmill test. The Bruce test protocol calls for 3-min stages of increasing belt speed and per cent grade on a treadmill (Marquette, 2000 treadmill; Marquette Electronics Inc., Milwaukee, WI, USA) [22]. Children were always tested in the presence of their parent(s). Each patient was allowed to familiarise themselves with the mouthpiece and the treadmill during a 3-min period prior to the start of the test. Each child was

\begin{tabular}{|c|c|c|c|}
\hline TABLE 1 & $\begin{array}{l}\text { Regression equations derived fror } \\
\text { growing children [16] }\end{array}$ & e o & a of \\
\hline Index & Equation & $\mathbf{R}^{2}$ & RSD \\
\hline \multicolumn{4}{|l|}{ Females } \\
\hline In RV & $2.61 \cdot(\ln ($ height) +0.056$) \cdot($ age-2.11) & 0.447 & 0.235 \\
\hline In TLC & $2.567 \cdot(\ln ($ height $)+0.030) \cdot($ age -0.168$)$ & 0.692 & 0.109 \\
\hline RV/TLC \% & $(13.157+0.589) \cdot$ age & 0.079 & 4.20 \\
\hline \multicolumn{4}{|l|}{ Males } \\
\hline In RV & $2.738 \cdot(\ln ($ height $)+0.067) \cdot($ age-2.375) & 0.616 & 0.239 \\
\hline In TLC & $2.698 \cdot($ In (height)-0.041) $\cdot($ age-0.412) & 0.866 & 0.101 \\
\hline RV/TLC \% & $(12.816+0.580) \cdot$ age & 0.063 & 4.27 \\
\hline
\end{tabular}

These regression equations were used to calculate the z-scores for the lung volume measurements. Height is expressed in $\mathrm{cm}$ and age in years. RSD: residual standard deviation; In: natural logarithm; RV: residual volume; TLC: total lung capacity. 


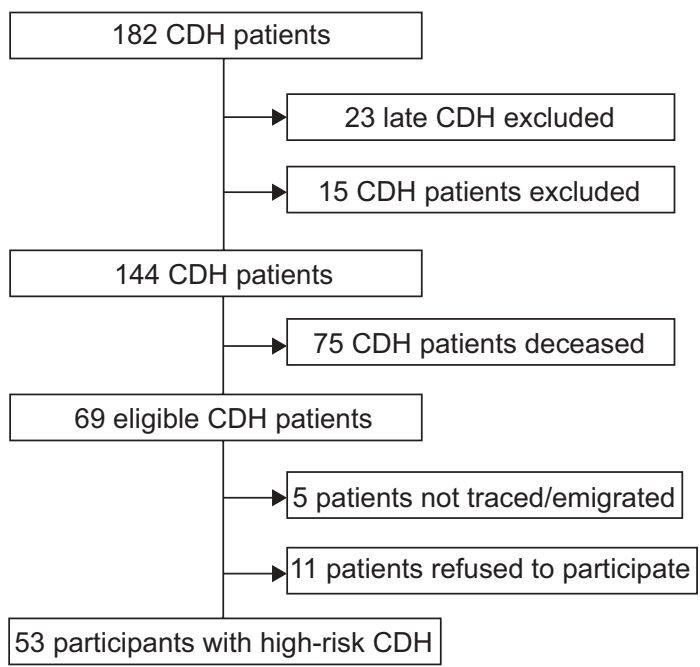

FIGURE 1. Exclusion and enrolment of the patients. $\mathrm{CDH}$ : congenital diaphragmatic hernia

urged to continue to the point of severe fatigue. Heart rate and oxygen saturation were monitored by finger pulse oximetry.

The parameters measured during the CPET were minute ventilation $\left(V^{\prime} \mathrm{E}\right)$, maximal oxygen uptake $\left(V^{\prime} \mathrm{O}_{2}, \mathrm{max}\right)$, oxygen pulse (i.e. oxygen uptake divided by the heart rate), respiratory exchange ratio, ratio of $V^{\prime} \mathrm{E}$ to carbon dioxide production $\left(V^{\prime} \mathrm{CO}_{2}\right)$, the respiratory rate and the duration of the exercise test. Respiratory gases were monitored on a breath-by-breath basis using a flow sensor (Vmax 229; SensorMedics).

The CPET was considered adequate if one or more of the following conditions were achieved: at least $80 \%$ of the maximum predicted heart rate (determined as 220 minus age), respiratory exchange ratio $>1.0$ during 1 min or exhaustion of the subject [23].

The $V^{\prime} \mathrm{O}_{2}$, max and the $V^{\prime} \mathrm{O}_{2}$, max per $\mathrm{kg}$ were expressed as $\mathrm{z}$ scores calculated from reference values [24]. Z-scores $<-1.96$ $\left(2.5^{\text {th }}\right.$ percentile of the reference population) were considered abnormally low.

\section{Statistical analysis}

Statistical analysis was performed using the unpaired t-test or the one-sample t-test with zero as reference for normally distributed continuous data. The Kolmogorov-Smirnov test was used to determine whether results were normally distributed. Nonparametric tests were used for non-normally distributed continuous data. The Fisher exact test or the Chisquared test was used for comparing categorical data. To explore the relationship between early (perinatal and neonatal) risk factors and lung function in later life, linear regression analysis with pulmonary function parameters and CPET results as dependent variables was performed. Statistical significance was defined as $\mathrm{p}<0.05$. SPSS 15.0 (SPSS Inc., Chicago, IL, USA) was used for data analysis.

\section{RESULTS}

\section{Patient characteristics}

In total, 182 patients born with $\mathrm{CDH}$ were referred to the Paediatric Surgical Centre of Amsterdam between 1987 and

\begin{tabular}{lccc}
\hline TABLE 2 & $\begin{array}{c}\text { Characteristics of participating and } \\
\text { nonparticipating patients did not differ } \\
\text { significantly }\end{array}$ \\
& Participating & Nonparticipating & p-value \\
\hline & 53 & 16 & \\
\hline Subjects $\mathbf{n}$ & $29(55)$ & $9(56)$ & 1.00 \\
Male & $3198 \pm 670$ & $3076 \pm 450$ & 0.52 \\
Birth weight g & $38.9 \pm 2.2$ & $39.4 \pm 1.7$ & 0.75 \\
Gestational age weeks & $8(15)$ & $2(13)$ & 1.00 \\
AS after $\mathbf{5}$ min $\leqslant \mathbf{5}$ & $45(85)$ & $13(81)$ & 1.00 \\
Symptoms $\leqslant \mathbf{6}$ h after birth & $45(85)$ & $16(100)$ & 0.22 \\
Left-sided CDH & $8.0(1-66)$ & $13.0(0-36)$ & 0.61 \\
Ventilation days & $19(36)$ & $7(44)$ & 0.63 \\
Patch reconstruction & $15(28)$ & $3(19)$ & 0.53 \\
Asthma in history & $19(36)$ & $8(50)$ & 0.40 \\
GORD in history & $8(15)$ & $5(31)$ & 0.15 \\
Cardiac abnormalities & $5(9)$ & $1(6)$ & 1.00 \\
\hline Recurrent CDH & & \\
\hline & &
\end{tabular}

1999, and the Sophia Children's Hospital in Rotterdam between 1988 and 1994; 84 of them survived. 15 patients were excluded because of treatment with ECMO (seven patients), mental retardation (three patients), trisomy 21 (two patients), pentalogy of Cantrell (one patient), pulmonary haemosiderosis (one patient) and missing patient files (one patient).

Of the 69 high-risk $\mathrm{CDH}$ patients eligible for this study, 53 $(77 \%)$ agreed to participate (fig. 1). 33 patients were treated in the Paediatric Surgical Centre of Amsterdam and 20 in the Sophia Children's Hospital.

A comparison of the 53 participating patients with those who were unwilling to participate disclosed no significant differences (table 2).

Four children were born before a gestational age of 36 weeks (minimum 31 weeks). $\mathrm{CDH}$ repair was performed a mean $\pm \mathrm{SD}$ of $2.8 \pm 3.7$ days (median 2 days, range 0-23 days) after birth. $\mathrm{CDH}$ repair was only performed when patients were stabilised and adequately oxygenated. Lung-protective ventilation strategies were used in both neonatal care units. Median hospital stay was 24 days (range 10-330 days).

Neurological abnormalities were reported in 13 (25\%) patients: 11 patients had a developmental delay and two patients had muscle tone abnormalities.

Persistent pulmonary hypertension of the neonate was well documented in only seven (13\%) cases, while in many files accurate information was missing. One patient was discharged with oxygen, which was continued for 3 months after discharge.

The mean \pm SD age at follow-up was $11.9 \pm 3.5$ yrs (range 6$18 \mathrm{yrs}$ ). None of the patients used antireflux medication at the time of follow-up. 
TABLE 3 Results of the spirometry and lung volume measurements of the congenital diaphragmatic hernia (CDH) patients

\begin{tabular}{|c|c|c|c|c|c|c|}
\hline & Mean \pm SD & Range & Mean \pm SD & Range & p-value & $\begin{array}{l}95 \% \mathrm{Cl} \text { of the } \\
\text { difference }\end{array}$ \\
\hline \multicolumn{7}{|c|}{ Before bronchodilation } \\
\hline \multicolumn{7}{|l|}{ Spirometry } \\
\hline Subjects $n$ & 48 & & 48 & & & \\
\hline FEV1/FVC & $-0.84 \pm 1.27$ & $-4.03-1.07$ & $0.05 \pm 0.90$ & $-2.04-1.90$ & $<0.001$ & $-1.33--0.44$ \\
\hline MMEF & $-1.57 \pm 1.70$ & $-6.18-1.08$ & $0.16 \pm 1.03$ & $-2.31-2.27$ & $<0.001$ & $-2.30--1.16$ \\
\hline $\mathrm{PEF} L \cdot \mathrm{S}^{-1}$ & $4.89 \pm 1.79$ & $1.42-8.23$ & $6.45 \pm 2.10$ & $3.16-10.34$ & $<0.001$ & $-2.34--0.78$ \\
\hline \multicolumn{7}{|c|}{ After bronchodilation } \\
\hline \multicolumn{7}{|l|}{ Spirometry } \\
\hline Subjects $\mathrm{n}$ & 38 & & & & & \\
\hline MMEF & $-0.22 \pm 1.30$ & $-5.54-2.19$ & & & & \\
\hline $\mathrm{PEF} L \cdot \mathrm{S}^{-1}$ & $5.38 \pm 1.80$ & $2.36-9.02$ & & & & \\
\hline \multicolumn{7}{|l|}{ Lung volumes } \\
\hline Subjects $n$ & 48 & & 29 & & & \\
\hline TLC & $0.16 \pm 1.91$ & $-4.16-1.55$ & $0.03 \pm 1.04$ & $-1.86-1.93$ & 0.70 & $-0.54-0.80$ \\
\hline RV & $0.98 \pm 2.06$ & $-5.37-2.44$ & $-0.24 \pm 0.84$ & $-2.17-0.98$ & 0.001 & $0.55-1.89$ \\
\hline RV/TLC \% & $26.7 \pm 9.0$ & $6-47$ & $20.4 \pm 3.0$ & $14-25$ & $<0.001$ & $3.50-9.13$ \\
\hline
\end{tabular}

Data are expressed as z-scores calculated from a reference population [20], unless otherwise stated. Cl: confidence interval; FEV1: forced expiratory volume in 1 s; FVC: forced vital capacity; MMEF: maximum mid-expiratory flow; PEF: peak expiratory flow; TLC: total lung capacity; RV: residual volume.

\section{Pulmonary function}

One patient was extremely anxious and therefore refused to perform the pulmonary function test. Spirometry and lung

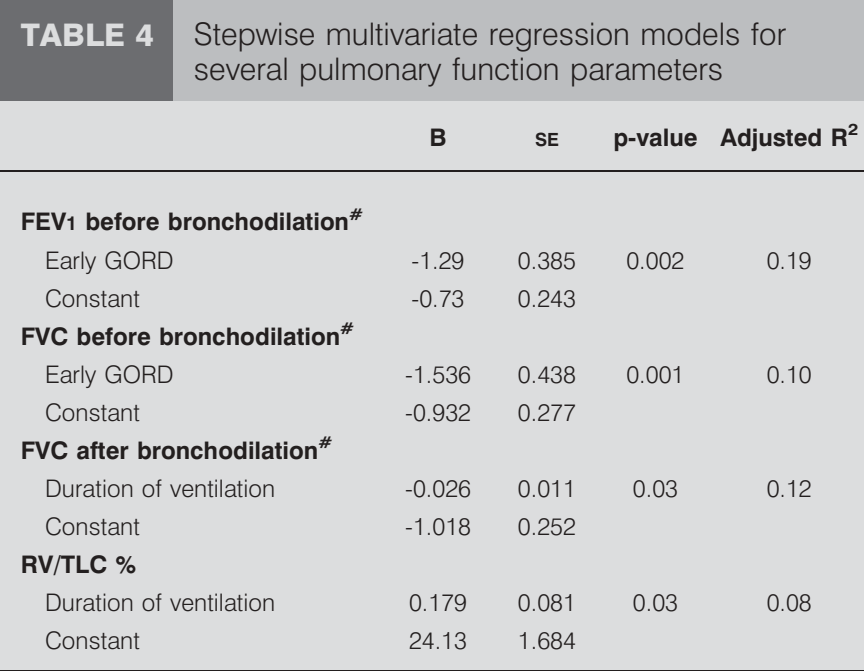

Independent variables were duration of ventilation, early gastro-oesophageal reflux disease (GORD; <2 yrs after congenital diaphragmatic hernia correction), side of defect, asthma in first grade family members, atopy and parental smoking. FEV1: forced expiratory volume in $1 \mathrm{~s}$; FVC: forced vital capacity; RV: residual volume; TLC: total lung capacity. ${ }^{\#}$ : expressed as z-scores. volume measurements of four $(8 \%)$ patients could not be reproduced and were excluded from analysis. In $10(19 \%)$ children, bronchodilator responsiveness was not tested because of technical difficulties.

Z-scores of all pulmonary function test results were normally distributed. The FEV1 z-score before bronchodilation was abnormally low $(<-1.64)$ in $22(46 \%) \mathrm{CDH}$ patients, compared with zero subjects in the control group $(\mathrm{p}<0.001)$; in twelve $\mathrm{CDH}$ patients there was a $>12 \%$ increase in FEV1 after bronchodilation (five not tested). In $12(25 \%)$ out of $48 \mathrm{CDH}$ patients the FEV1/FVC z-score was abnormally low $(<-1.64)$ before bronchodilation, compared with three $(6 \%)$ subjects in the control group $(p=0.007)$. Mean FEV1, FVC, FEV1/FVC, MMEF and PEF were significantly lower in $\mathrm{CDH}$ patients compared with the control group (table 3).

The RV/TLC ratio z-score was $>+1.64$ in 25 (52\%) patients, compared with zero subjects in the control group $(\mathrm{p}<0.001)$; in $19(76 \%)$ this was due to an elevated RV, in five (20\%) to a decreased TLC, and in one (4\%) patient to a combination.

Restrictive impairment (TLC z-score $<-1.64$ ) was demonstrated in eight $(17 \%)$ patients, compared with zero subjects in the control group $(\mathrm{p}=0.02)$.

Linear regression analysis disclosed a negative association between gastro-oesophageal reflux disease (GORD) and both FEV1 and FVC before bronchodilation (table 4). Patients who were ventilated for $\geqslant 7$ days had significantly lower $z$-scores 

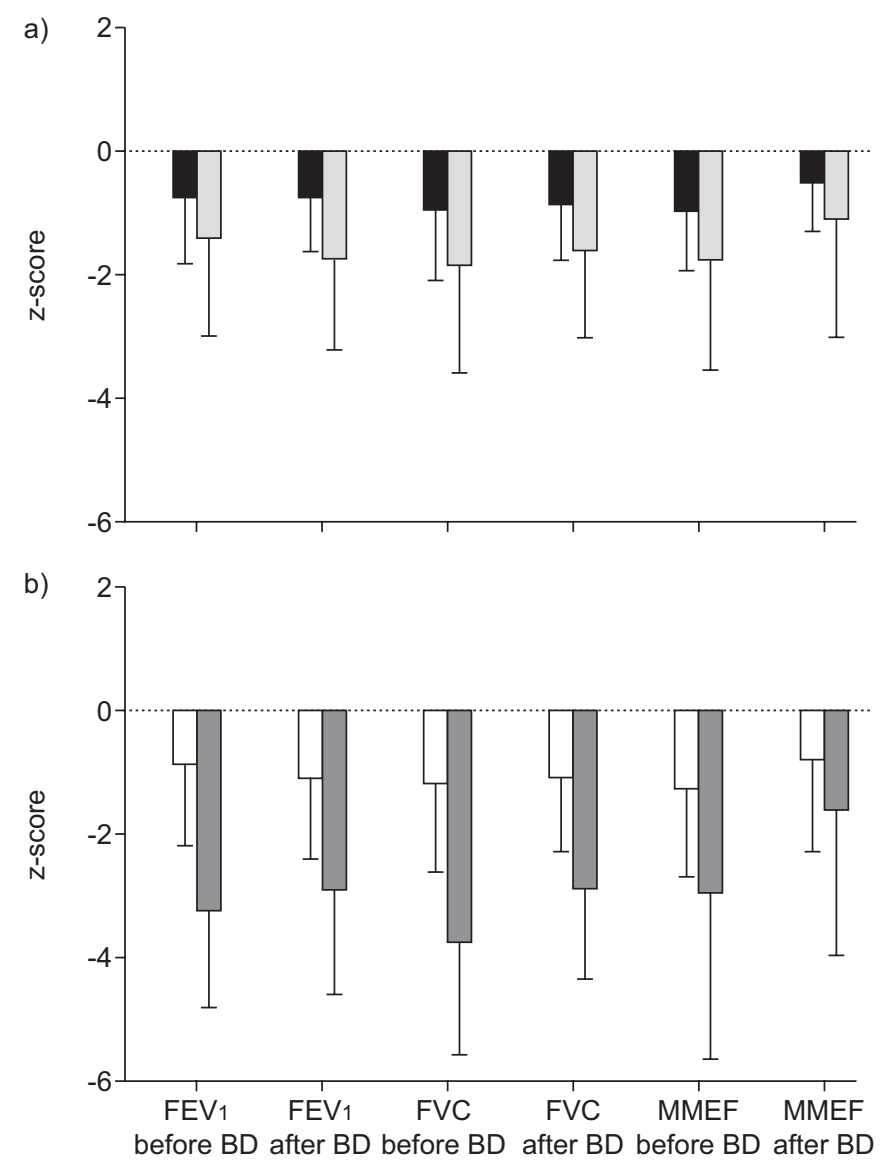

FIGURE 2. Comparison of pulmonary function parameters in a) patients ventilated for $\geqslant 7$ days $(\square)$ versus patients ventilated $<7$ days $(\square)$ and b) patients requiring antireflux surgery $(\square)$ versus no antireflux surgery $(\square)$. All lung function parameters are expressed as z-scores according to StANOJEVIC et al. [20]. FEV1: forced expiratory volume in $1 \mathrm{~s}$; BD: bronchodilation; FVC: forced vital capacity; MMEF: maximum mid-expiratory flow.

for FEV1 after bronchodilation and FVC before bronchodilation (fig. 2a). Patients who had undergone antireflux surgery had significantly lower z-scores for FEV1, FVC, MMEF (fig. 2b) and TLC. There was a trend towards higher age at follow-up and lower $z$-scores for FEV1 $(p=0.051$; fig. 3a) and FEV1/FVC $(p=0.06$; fig. $3 c)$ in $\mathrm{CDH}$ patients. There was no association between age and the $z$-score for FVC ( $p=0.22$; fig. $3 b)$.

\section{Maximum exercise testing}

Eight patients did not perform CPET for the following reasons: refusal (five patients), technical problems (two patients) and severely impaired pulmonary function (FEV1 z-score -7.14; one patient). Pulmonary function results were significantly lower for patients who did not perform the CPET (FEV1 z-score -3.93 versus $-1.10 ; \mathrm{p}=0.002$; and FEV1/FVC $\mathrm{z}$-score -2.49 versus -0.76 ; $\mathrm{p}=0.02)$.

In total, 45 patients underwent CPET. The results of nine patients were excluded from analysis because they did not reach the level of maximal exercise due to painful legs (six patients), mild motor skills disorder (one patient), shortness of breath (one patient) and being too small to fulfil the protocol
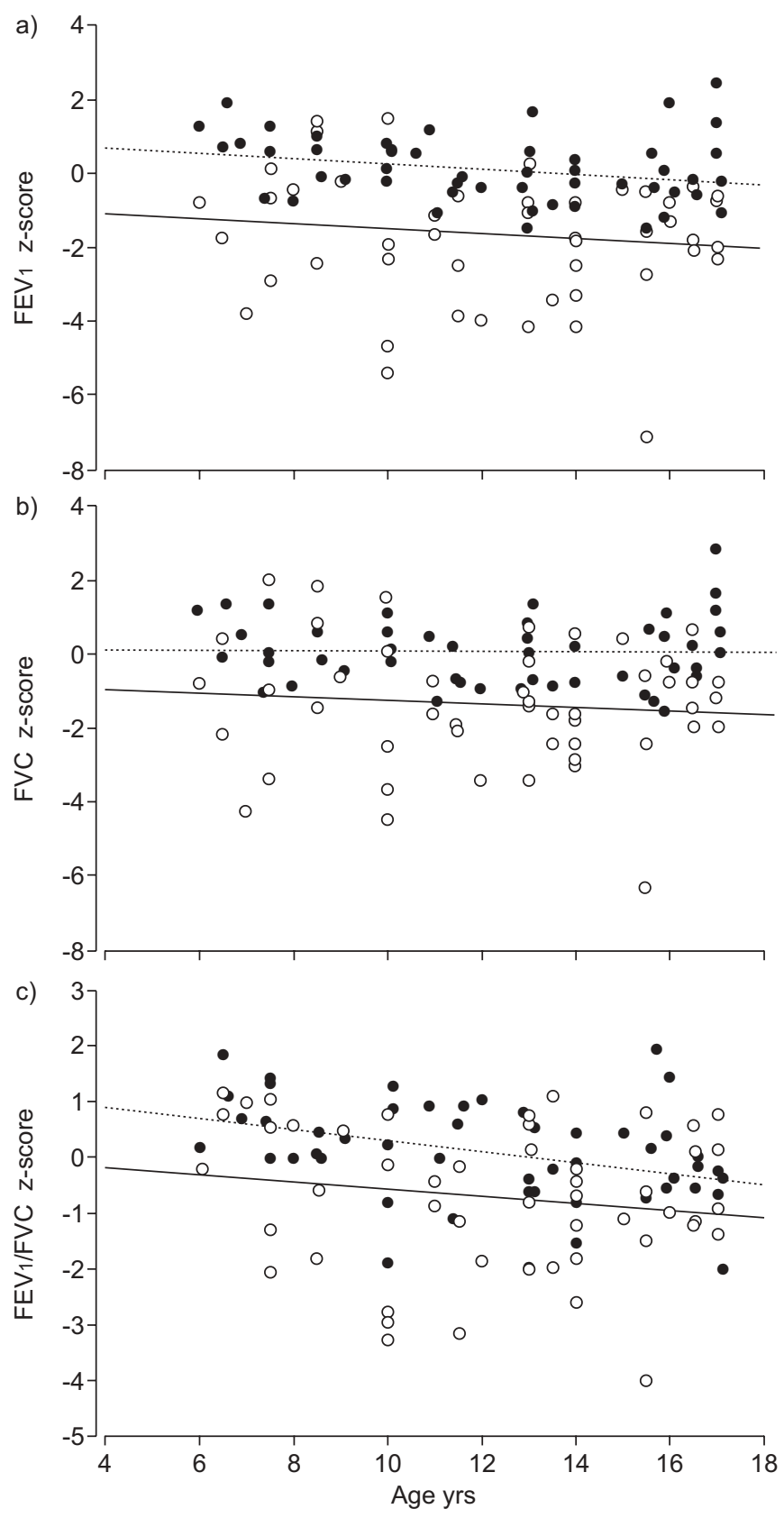

FIGURE 3. Relationships between lung function results and age at follow-up. Lung function results are expressed as z-scores according to STANOJEVIC et al. [20]. FEV1: forced expiratory volume in $1 \mathrm{~s}$; FVC: forced vital capacity. $\bullet$ : control group; $\bigcirc$ : congenital diaphragmatic hernia $(\mathrm{CDH})$ group; __ : regression lines derived from data of the control group; …... regression lines derived from data of the $\mathrm{CDH}$ group.

(one patient). Six of them had a history of developmental delay, which might have influenced exercise performance. Pulmonary function results of the patients who did not achieve maximal exercise were similar to those who did. Four children had mild transcutaneous desaturation (transcutaneous oxygen saturation $84-94 \%$ ) during CPET; two of them did not achieve maximal exercise due to painful legs.

Reliable exercise data could be obtained in 36 children and showed that three children had an abnormally low $V^{\prime} \mathrm{O}_{2}$, max 


\begin{tabular}{|c|c|c|}
\hline Parameter & Mean \pm SD & $95 \% \mathrm{Cl}$ \\
\hline fc max \% pred & $97.7 \pm 1.3$ & $96.4-99.4$ \\
\hline$f \mathrm{R}$ max breaths $\mathrm{min}^{-1}$ & $57.9 \pm 14.4$ & $53.0-62.9$ \\
\hline Respiratory exhange ratio & $1.09 \pm 0.13$ & $1.05-1.13$ \\
\hline$V^{\prime} E \max L \cdot \min ^{-1}$ & $71.4 \pm 26.8$ & $62.3-80.4$ \\
\hline Oxygen pulse \% pred & $102.7 \pm 17.1$ & $96.4-108.9$ \\
\hline$V^{\prime} \mathrm{O}_{2}$, max Z-score & $-0.23 \pm 1.58$ & $-0.77-0.31$ \\
\hline$V^{\prime} \mathrm{O}_{2}$, max per kg z-score & $-0.25 \pm 1.28$ & $-0.68-0.18$ \\
\hline$V^{\prime} E / V^{\prime} \mathrm{CO}_{2} L \cdot \min ^{-1}$ & $31.1 \pm 5.6$ & $29.2-33.0$ \\
\hline Stc, $\mathrm{O}_{2} \%$ & $95.3 \pm 3.0$ & $94.1-96.5$ \\
\hline Exercise duration z-score & $0.79 \pm 1.2$ & $0.40-1.18$ \\
\hline
\end{tabular}

$\mathrm{Cl}$ : confidence interval; $f \mathrm{C}$ : cardiac frequency; fR: respiratory frequency; $V^{\prime} \mathrm{E}$ : minute ventilation; $V^{\prime} \mathrm{O}_{2}$,max: maximal oxygen uptake; $V^{\prime} \mathrm{CO}_{2}$ : carbon dioxide production; $\mathrm{Stc}, \mathrm{O}_{2}$ : transcutaneous oxygen saturation.

z-score $(<-1.96)$. In one child this was accompanied by a reduced peak oxygen pulse (oxygen pulse $\leqslant 80 \%$ predicted), whereas two patients had airway obstruction (FEV1/FVC zscore -2.80 and -2.00$)$. Overall, the mean $\pm \mathrm{SD} V^{\prime} \mathrm{O}_{2}$, max $\mathrm{Z}$-score did not differ significantly from normal values $(-0.23 \pm 1.58$; $\mathrm{p}=0.39$; table 5).

Linear regression analysis showed that the $V^{\prime} \mathrm{O}_{2}$, max $\mathrm{z}$-score was positively associated with FEV1 Z-score before bronchodilation $\left(R^{2}=0.27 ; p=0.001\right)$, after correction for duration of ventilation, parental smoking, sport practice and exercise tolerance.

\section{DISCUSSION}

We found mild to moderate pulmonary function abnormalities in children and adolescents born with high-risk $\mathrm{CDH}$ compared with a matched control group. Linear regression analysis revealed that GORD in the first 2 yrs after repair was an independent determinant of a reduced FEV1 and FVC. Furthermore, our study demonstrated that the majority of patients had a normal exercise capacity and cardiorespiratory response.

Reduced FEV1, FVC, FEV1/FVC and MMEF were found in almost half of the CDH survivors, compared with $\sim 0 \%$ in the control group. Obstructive airways disease in these patients may be due to distorted airway architecture due to pulmonary hypoplasia or ventilator-induced barotrauma. When comparing $\mathrm{CDH}$ patients who were ventilated for $<7$ days with patients ventilated for $\geqslant 7$ days, we found a significantly lower FEV1 after bronchodilation in the latter group, which may reflect severity of (CDH-related) pulmonary disease or ventilator-induced barotrauma. This finding is in agreement with earlier studies $[14,25]$. The increased RV/TLC ratio might be due to obstructive impairment. However, it has been demonstrated that the size of the alveoli themselves increases, resulting in alveolar distension and consequently hyperinflation $[6,13]$, which may also cause an increased RV/TLC ratio $[25,26]$. Overall, CDH patients appeared not to have an important reduction of TLC in their school and adolescent years [25-27].
It has been suggested that delayed $\mathrm{CDH}$ repair and lungprotective ventilation strategies might prevent ventilatorinduced lung injury $[4,8]$. Nonetheless, our results are similar to those of the study of IJSSELSTIJN et al. [25], in which CDH patients were operated on immediately after birth, implying that neonatal management, particularly ventilation strategy, is not a major determinant of long-term lung function in highrisk $\mathrm{CDH}$.

Nine children had significant bronchodilator responsiveness. Only two of these children were currently treated with inhaled steroids and/or $\beta$-mimetics. All children had shortness of breath, although they did not experience this as abnormal. This suggests that both parents and physicians tend to underestimate the significance of respiratory symptoms in children born with $\mathrm{CDH}$. This might be due to their willingness to accept symptoms that they assume are due to the underlying congenital abnormality in the lung, as well as the fact that many patients have been living with obstructive airway pathology since birth and might, therefore, not fully apprehend their respiratory limitations. This phenomenon has been previously reported [27].

Linear regression analysis demonstrated that GORD in the first 2 yrs after repair was an independent predictor for a reduction in FEV1. An association between airway obstruction and GORD has been suggested before, but is controversial [28]. It may be speculated that prolonged microscopic aspiration of gastric acid into the airways, and potentially into the alveoli, may cause chronic pulmonary inflammation and pulmonary fibrosis. SCHACHTER et al. [29] found that adult patients with severe GORD have a reduced diffusion capacity compared with patients without GORD. There are no pulmonary function studies describing the long-term follow-up of infants with severe GORD, although it has been reported that children born with oesophageal atresia and radiologically demonstrated GORD in early childhood had airway obstruction more often, and smaller lung volumes, 6-37 yrs after repair of oesophageal atresia, compared with children born with oesophageal atresia without GORD [30].

Despite the pulmonary function abnormalities, all children except three reached a normal $V^{\prime} \mathrm{O}_{2}$,max. It should be noted, however, that results in nine patients were excluded and eight patients could not perform the CPET. We cannot exclude possible selection bias regarding the CPET, since patients with the poorest pulmonary function did not perform the test.

The reduced $V^{\prime} \mathrm{O}_{2}$, max in three patients is most probably due to airway abnormalities. A reduced $V^{\prime} \mathrm{O}_{2}$, max due to a decreased level of fitness is less likely, because two of the three patients practised sports twice a week.

Our study demonstrated that the majority of patients tested had a normal exercise capacity and cardiorespiratory response. Mean duration of CPET was even longer than expected. During exercise, four children had mild desaturation with a normal oxygen pulse and $V^{\prime} \mathrm{E} / V^{\prime} \mathrm{CO}_{2}$, indicating that measurement of saturation was unsatisfactory due to perspiration and movement.

We studied a relatively large group of school-aged high-risk $\mathrm{CDH}$ survivors. Although our control group was not recruited 
specifically for this study, measurements were made in similar age groups and with comparable techniques. The cohort had similar neonatal characteristics compared with those survivors who did not participate. We therefore infer that the results from our cohort are representative of the entire group of surviving $\mathrm{CDH}$ patients that present with early respiratory symptoms.

We recognise that, despite using z-scores based on a healthy reference population for the CPET, a control group is preferable. Another limitation is the broad age range of the studied patients, which is almost inevitable due to the relatively low incidence of $\mathrm{CDH}$ and the high mortality. We used z-scores to compensate for the age difference.

In conclusion, we demonstrated that survivors of high-risk $\mathrm{CDH}$ have mild to moderate pulmonary function abnormalities, which might be related to GORD in the first years after $\mathrm{CDH}$ repair. Future research is recommended in order to investigate the relationship between GORD after $\mathrm{CDH}$ repair and pulmonary function abnormalities in later life.

Exercise capacity and oxygen uptake is probably normal in these patients, indicating that they are not at risk of developing long-term pulmonary vascular pathology. Nevertheless, our results demonstrate that periodical evaluation of cardiorespiratory function in all $\mathrm{CDH}$ survivors is mandatory, with particular attention to the role of GORD, as subjects tend to underestimate their symptoms.

\section{STATEMENT OF INTEREST}

None declared.

\section{ACKNOWLEDGEMENTS}

We thank D. Houthuijs (Centre for Environmental Health Research, National Institute for Public Health and the Environment, Bilthoven, the Netherlands) and B. Brunekreef (Institute for Risk Assessment Sciences, Utrecht University, and Julius Center for Health Sciences and Primary Care, University Medical Center Utrecht, Utrecht, the Netherlands) for providing the data of the control group.

\section{REFERENCES}

1 Vanamo K. A 45-year perspective of congenital diaphragmatic hernia. Br J Surg 1996; 83: 1758-1762.

2 Colvin J, Bower C, Dickinson JE, et al. Outcomes of congenital diaphragmatic hernia: a population-based study in Western Australia. Pediatrics 2005; 116: e356-e363.

3 Stege G, Fenton A, Jaffray B. Nihilism in the 1990s: the true mortality of congenital diaphragmatic hernia. Pediatrics 2003; 112: 532-535.

4 Sakurai Y, Azarow K, Cutz E, et al. Pulmonary barotrauma in congenital diaphragmatic hernia: a clinicopathological correlation. J Pediatr Surg 1999; 34: 1813-1817.

5 Beals DA, Schloo BL, Vacanti JP, et al. Pulmonary growth and remodeling in infants with high-risk congenital diaphragmatic hernia. J Pediatr Surg 1992; 27: 997-1001.

6 Hislop A, Reid L. Persistent hypoplasia of the lung after repair of congenital diaphragmatic hernia. Thorax 1976; 31: 450-455.

7 Wilson JM, Lund DP, Lillehei CW, et al. Congenital diaphragmatic hernia - a tale of two cities: the Boston experience. J Pediatr Surg 1997; 32: 401-405.

8 Azarow K, Messineo A, Pearl R, et al. Congenital diaphragmatic hernia - a tale of two cities: the Toronto experience. J Pediatr Surg 1997; 32: 395-400.
9 Bos AP, Hussain SM, Hazebroek FW, et al. Radiographic evidence of bronchopulmonary dysplasia in high-risk congenital diaphragmatic hernia survivors. Pediatr Pulmonol 1993; 15: 231-234.

10 Shehata SM, Sharma HS, van der Staak FH, et al. Remodeling of pulmonary arteries in human congenital diaphragmatic hernia with or without extracorporeal membrane oxygenation. J Pediatr Surg 2000; 35: 208-215.

11 Shehata SM, Tibboel D, Sharma HS, et al. Impaired structural remodelling of pulmonary arteries in newborns with congenital diaphragmatic hernia: a histological study of 29 cases. J Pathol 1999; 189: 112-118.

12 Muratore CS, Kharasch V, Lund DP, et al. Pulmonary morbidity in 100 survivors of congenital diaphragmatic hernia monitored in a multidisciplinary clinic. J Pediatr Surg 2001; 36: 133-140.

13 Falconer AR, Brown RA, Helms P, et al. Pulmonary sequelae in survivors of congenital diaphragmatic hernia. Thorax 1990; 45: 126-129.

14 Stefanutti G, Filippone M, Tommasoni N, et al. Cardiopulmonary anatomy and function in long-term survivors of mild to moderate congenital diaphragmatic hernia. J Pediatr Surg 2004; 39: 526-531.

15 Arena F, Baldari S, Centorrino A, et al. Mid- and long-term effects on pulmonary perfusion, anatomy and diaphragmatic motility in survivors of congenital diaphragmatic hernia. Pediatr Surg Int 2005; 21: 954-959.

16 Smeets M, Brunekreef B, Dijkstra L, et al. Lung growth of preadolescent children. Eur Respir J 1990; 3: 91-96.

17 Schrader PC, Quanjer PH, van Zomeren BC, et al. Selection of variables from maximum expiratory flow-volume curves. Bull Eur Physiopathol Respir 1983; 19: 43-49.

18 Quanjer PH, Tammeling GJ, Cotes JE, et al. Lung volumes and forced ventilatory flows. Report Working Party Standardization of Lung Function Tests, European Community for Steel and Coal. Official Statement of the European Respiratory Society. Eur Respir J 1993; 6: Suppl. 16, 5-40.

19 Newth CJ, Enright P, Johnson RL. Multiple-breath nitrogen washout techniques: including measurements with patients on ventilators. Eur Respir J 1997; 10: 2174-2185.

20 Stanojevic S, Wade A, Stocks J, et al. Reference ranges for spirometry across all ages: a new approach. Am J Respir Crit Care Med 2008; 177: 253-260.

21 Sterk PJ, Quanjer PH, van Zomeren BC, et al. The single breath nitrogen test in epidemiological surveys; an appraisal. Bull Eur Physiopathol Respir 1981; 17: 381-397.

22 Bruce RA, Kusumi F, Hosmer D. Maximal oxygen intake and nomographic assessment of functional aerobic impairment in cardiovascular disease. Am Heart J 1973; 85: 546-562.

23 American Thoracic Society, American College of Chest Physicians, ATS/ACCP Statement on cardiopulmonary exercise testing. Am J Respir Crit Care Med 2003; 167: 211-277.

24 Binkhorst RA, Hof van 't MA, Saris WHM. Maximale inspanning door kinderen; referentiewaarden voor 6-18 jarige meisjes en jongens [Maximum exercise in children; reference values for 6-18 year old girls and boys]. The Hague, Dutch Heart Association, 1992.

25 IJsselstijn H, Tibboel D, Hop WJ, et al. Long-term pulmonary sequelae in children with congenital diaphragmatic hernia. Am J Respir Crit Care Med 1997; 155: 174-180.

26 Marven SS, Smith CM, Claxton D, et al. Pulmonary function, exercise performance, and growth in survivors of congenital diaphragmatic hernia. Arch Dis Child 1998; 78: 137-142.

27 Trachsel D, Selvadurai H, Bohn D, et al. Long-term pulmonary morbidity in survivors of congenital diaphragmatic hernia. Pediatr Pulmonol 2005; 39: 433-439.

28 Field SK, Underwood M, Brant R, et al. Prevalence of gastroesophageal reflux symptoms in asthma. Chest 1996; 109: 316-322. 
29 Schachter LM, Dixon J, Pierce RJ, et al. Severe gastroesophageal reflux is associated with reduced carbon monoxide diffusing capacity. Chest 2003; 123: 1932-1938.
30 Chetcuti P, Phelan PD, Greenwood R. Lung function abnormalities in repaired oesophageal atresia and tracheo-oesophageal fistula. Thorax 1992; 47: 1030-1034. 